\title{
BMJ Open Integration of sexually transmitted infection (STI) services into HIV care and treatment services for women living with HIV: a systematic review
}

\author{
Caitlin E Kennedy, ${ }^{1}$ Sabina A Haberlen, ${ }^{1}$ Manjulaa Narasimhan ${ }^{2}$
}

To cite: Kennedy CE, Haberlen SA, Narasimhan M. Integration of sexually transmitted infection (STI) services into HIV care and treatment services for women living with HIV: a systematic review. BMJ Open 2017;7:e015310. doi:10.1136/ bmjopen-2016-015310

- Prepublication history and additional material are available. To view these files please visit the journal online (http://dx.doi org/10.1136/bmjopen-2016015310)

Received 2 December 2016 Revised 24 February 2017 Accepted 23 March 2017

\section{CrossMark}

${ }^{1}$ Departments of International Health and Epidemiology, Johns Hopkins University Bloomberg School of Public Health, Baltimore, Maryland, USA ${ }^{2}$ Department of Reproductive Health and Research, World Health Organization, Geneva, Switzerland

Correspondence to Dr Caitlin E Kennedy; caitlinkennedy@jhu.edu

\section{ABSTRACT}

Objective To review and critically appraise the existing evidence on integration of sexually transmitted infection (STI) services into HIV care and treatment services for women living with HIV.

Design Systematic review.

Data sources Four electronic databases were searched through 16February 2017 using keywords for HIV, STIs and integration. Reference lists of included articles and other reviews were also screened.

Review methods We included studies that compared women living with HIV who received STI services integrated into HIV care and treatment services with those who received HIV care and treatment services without integrated STI services or standard of care.

Results 0 f 170 articles identified, 3 studies reported in 4 articles were included. Two studies evaluated comprehensive care for people living with HIV in the UK; in both cases, quality and uptake of STI services seemed to improve following integration. The third study conducted a comparative case study across different models of care in Swaziland: two clinics integrated with sexual and reproductive health services (including STI services), and two stand-alone HIV clinics (without STI services). Coverage for Pap smears among women living with HIV was higher at the fully integrated site, but there was no significant difference in the prevalence of sexual health screening or advice on sexual health. Reported client satisfaction was generally higher at the standalone HIV clinic, and a diverse range of factors related to implementation of different care models challenged the notion that integrated services are always superior or desired.

Conclusion While there is a limited evidence base for integrating STI services into HIV care and treatment services, existing studies indicate that integration is feasible and has the potential for positive outcomes. However, diverse population needs and health system factors must be considered when designing models of care to provide STI services to women living with HIV.

\section{BACKGROUND}

The United Nations 2030 Agenda for Sustainable Development defines a set of ambitious global health goals and targets, including the need to ensure healthy lives and promote
Strengths and limitations of this study

Examining the evidence for integrating two related health services-sexually transmitted infection (STI) services and HIV services-for women living with HIV who have specific needs.

- Systematic search, screening and data abstraction process to evaluate the global literature on integration of STI services into HIV care and treatment services.

- While few studies were identified that met the inclusion criteria, the existing data indicate that integration can be feasible and can have positive outcomes, though differences were seen across settings and populations.

well-being for all at all ages (Goal 3). ${ }^{1}$ To ensure the health sector implementation of this Agenda, WHO has developed global health sector strategies on HIV, viral hepatitis and sexually transmitted infections (STIs) which were adopted by the United Nations Member States in May 2016. ${ }^{2-4}$ Among the common priorities across the three strategies is the imperative to strengthen health systems to support integrated service delivery by identifying the best methods and approaches for delivering a continuum of high-impact, tailored health interventions and services to different populations and in different locations in order to achieve equity and ensure quality.

It is estimated that annually there are 357 million new cases of four curable STIs among people aged 15-49 years: Chlamydia trachomatis (131 million), Neisseria gonorrhoeae (78 million), syphilis (6 million) and Trichomonas vaginalis ( 142 million). ${ }^{4}$ That translates to nearly 1 million new infections per day. The prevalence of some viral STIs is similarly high, with an estimated 417 million people infected with herpes simplex type 2 and approximately 291 million women harbouring the 
human papillomavirus. ${ }^{4}$ STIs have clear negative health consequences, including fetal and neonatal death and disability, cervical cancer and infertility, as well as physical, social and psychological effects. ${ }^{45}$ There is substantial evidence that STIs also increase HIV transmissibility as well as HIV acquisition risk by as much as $2-3$ times in some populations. ${ }^{46}$

For women living with HIV, a holistic and comprehensive approach to sexual and reproductive health and rights includes enhancing services to identify and treat STIs. Women living with HIV have high rates of STI coinfection; a recent systematic review of 37 studies found a mean STI prevalence among these women of $15.8 \%$ (SD 9.9). ${ }^{7}$ Screening and treatment for STIs have been recommended as a part of the package of care for people living with $\mathrm{HIV}$ by $\mathrm{WHO}^{89}$; they are also part of the U.S. President's Emergency Plan for AIDS Relief (PEPFAR)'s minimum package of prevention services for people living with HIV. ${ }^{10}$ While many national HIV treatment guidelines (including those in the UK, the USA and South Africa) recommend that STI screening occurs within routine HIV care visits, published service statistics indicates that coverage rates for the recommended sexual history and STI screening are often very low. ${ }^{11-14}$ For example, among a nationally representative sample of women in HIV treatment in the USA, the coverage of testing from 2008 to 2010 among sexually active women was only $49 \%$ for syphilis, $30 \%$ for chlamydia and $28 \%$ for gonorrhoea. ${ }^{15}$

A key approach to increasing coverage of STI services for people living with HIV is integration of these services within HIV care and treatment settings. As part of an effort to inform updated WHO guidelines on sexual and reproductive health and rights for women living with HIV, we sought to systematically review the evidence for the integration of STI services into HIV care and treatment services for women living with HIV. Our goal was to identify the models of integrating STI services into HIV care and treatment services for people living with HIV that have been evaluated and their associated outcomes.

\section{METHODS \\ Definitions}

There is no agreed upon definition of service integration and no clear distinction between integrated and non-integrated services. ${ }^{16}$ WHO has defined integration as the 'management and delivery of health services so that clients receive a continuum of preventive and curative services, according to their needs over time and across different levels of the health system'. ${ }^{17}$ For the purposes of this review, we used this definition of integration and focus on the service delivery level, rather than at the policy or other levels.

We considered STI services to include sexual history screening, information and advice on avoiding re/infection, access to partner notification services and disclosure support, when appropriate, and testing, treatment and/ or syndromic management of any STIs other than HIV since we were looking at the integration of STI services with HIV services. The integration of cervical cancer screening by Pap tests (or smears) into HIV care and treatment settings absent of one or more of the aforementioned STI services was not considered sufficient to constitute integrated STI services.

\section{Research question and inclusion criteria}

The review addressed the following research question in population, intervention, comparison and outcomes (PICO) format: should STI services be integrated into HIV care and treatment services for women living with HIV?

\section{Population}

Women living with HIV.

\section{Intervention}

STI services, including STI testing, STI treatment and/ or syndromic management, integrated into HIV care and treatment services.

\section{Comparison}

HIV care and treatment services without integrated STI services or standard of care.

\section{Outcomes}

(1) Uptake of STI services, (2) STIs (reinfection), (3) client satisfaction and service quality (interpreted broadly to include receipt of sexual and reproductive health or HIV services, etc) and (4) provider knowledge and attitudes about STI services for women living with HIV.

To be included in the review, an article had to meet the following criteria:

1. Comparative study (any study design with pre/ post or multiarm outcome comparisons) examining women living with HIV who received STI servicesincluding STI testing, STI treatment and syndromic management-integrated into HIV care and treatment services, compared with women living with HIV who received HIV care and treatment services without integrated STI services or standard of care.

2. Evaluated one or more of the key outcomes outlined in the PICO question above.

3. Published in a peer-reviewed journal prior to 16 February 2017.

Because this review was designed to inform WHO guidelines on sexual and reproductive health and rights of women living with $\mathrm{HIV},{ }^{18}$ we excluded studies conducted only among men (primarily populations of men who have sex with men), but included studies conducted among both women and men. No restrictions were placed based on location of the intervention. No language restrictions were used on the search. We followed Preferred Reporting Items for Systematic Reviews and Meta-Analyses (PRISMA) guidelines for reporting systematic review 
results. ${ }^{19} \mathrm{~A}$ full review protocol was developed and is available from the corresponding author on request.

\section{Search strategy}

We searched the following electronic databases for articles published anytime through the search date of 16 February 2017: PubMed, CINAHL and EMBASE. Search terms were developed for STIs, HIV and integration and combined; the full search strategy for each database is available in online supplementary file 1 . Secondary reference searching was conducted on all studies included in the review and three other related reviews. ${ }^{20-22}$

\section{Screening abstracts}

Titles, abstracts, citation information and descriptor terms of citations identified through the search strategy underwent an initial screening by a member of the study staff. Remaining abstracts then were screened in duplicate by two reviewers working independently with adjudication of differences by a senior member of the study team. Fulltext articles were obtained of all selected abstracts, and two independent reviewers assessed all full-text articles for eligibility to determine final study selection.

\section{Data extraction and management}

For each study, the following information was extracted: study citation, location, setting, target group, intervention description, study design, unit of analysis, selection of participants, sample size, age, gender and reported numerical outcomes and results.

Assessment of study rigour was conducted based on a nine-item tool, including items for (1) study design includes preintervention/postintervention data, (2) study design includes control or comparison group, (3) study design includes cohort, (4) comparison groups equivalent at baseline on sociodemographics, (5) comparison groups equivalent at baseline on outcome measures, (6) random assignment (group or individual) to the intervention, (7) participants randomly selected for assessment, (8) control for potential confounders and (9) follow-up rate $\geq 75 \%$. This tool was based on the eight-item rigour assessment for systematic reviews of HIV behavioural interventions with a range of study designs (beyond randomised trials) developed by the Evidence Project. $^{23} 24$

\section{Data analysis}

Data were analysed according to coding categories and outcomes. Meta-analysis was not conducted due to the small number of included studies.

\section{RESULTS}

Online database searching yielded 406 hits, of which there were 235 unique citations after removing duplicates (figure 1). After initial screening of titles and abstracts, 104 citations remained for double-screening. These were double-screened and 40 were pulled for full-text review.
Of these, one study (reported in two articles) was considered eligible for inclusion. In addition, two studies were included from the prior systematic review covering articles through $2007 .{ }^{20}$ Therefore, a total of three studies reported in four articles met the criteria for inclusion in the review. Table 1 presents descriptions of the study settings, methods and outcomes. Table 2 presents an assessment of study rigour.

Of the three included articles, two evaluated the creation of new sexual health clinics within existing services for people living with HIV in the UK. The first study evaluated an integrated sexual healthcare clinic for HIV-positive women that included screening for STIs, along with other sexual health services including contraception, preconception counselling and cervical cytology. ${ }^{25}$ The per cent of clients who were offered an STI screening increased from $70 \%$ before integration to $83 \%$ at 12-month follow-up. Other measures of service quality, including recording of sexual history and uptake of cervical cytology, also improved. In the second study, a sexual health clinic was similarly opened for HIV-positive adults that included STI screening, along with other services including hepatitis $\mathrm{B}$, vaccination and cervical smear testing. ${ }^{26}$ The per cent of clients receiving an annual STI screening increased from $26 \%$ before integration to $46 \%$ afterwards $(\mathrm{p}=0.003)$, while the per cent receiving an STI screening at their first appointment increased from $39 \%$ to $52 \%(\mathrm{p}=0.065)$. Other measures of service quality, including documentation that an annual health discussion had taken place between provider and patient and uptake of cervical cytology, also generally improved. ${ }^{26}$

The final study, reported in two articles, ${ }^{27}{ }^{28}$ was a comparative case study examining the relationship between integration and the use and demand for sexual and reproductive health services (including STI services), and client satisfaction across different models of care in Swaziland: two clinics integrated with sexual and reproductive health services and two stand-alone HIV clinics (which did not provide STI services). In addition to employing a different study design than the previous two studies (a comparison across clinic models rather than a comparison before and after initiation of new services), this study had slightly higher overall rigour assessment as it randomly selected clients for assessment and adjusted for confounders (table 2). An exit survey $(\mathrm{n}=602)$ measured service use and satisfaction across models using logistic regression; a complementary qualitative assessment was also conducted. Women attending the fully integrated site were more likely to have had a Pap smear since testing positive than women attending the less integrated service models $(35 \%$ vs $11 \%, 14 \%$ and $10 \%, \mathrm{p}<0.001)$. However, clients attending the fully integrated site were not more likely to report having sexual health screening ( $45 \%$ vs $57 \%, 76 \%$ and $42 \%$ from most to least integrated, respectively) or advice on sexual health $(16 \%$ vs $12 \%, 16 \%$ and $11 \%$ from most to least integrated). Client satisfaction was higher in the fully stand-alone clinic compared with both the partially integrated site (adjusted OR (aOR) 


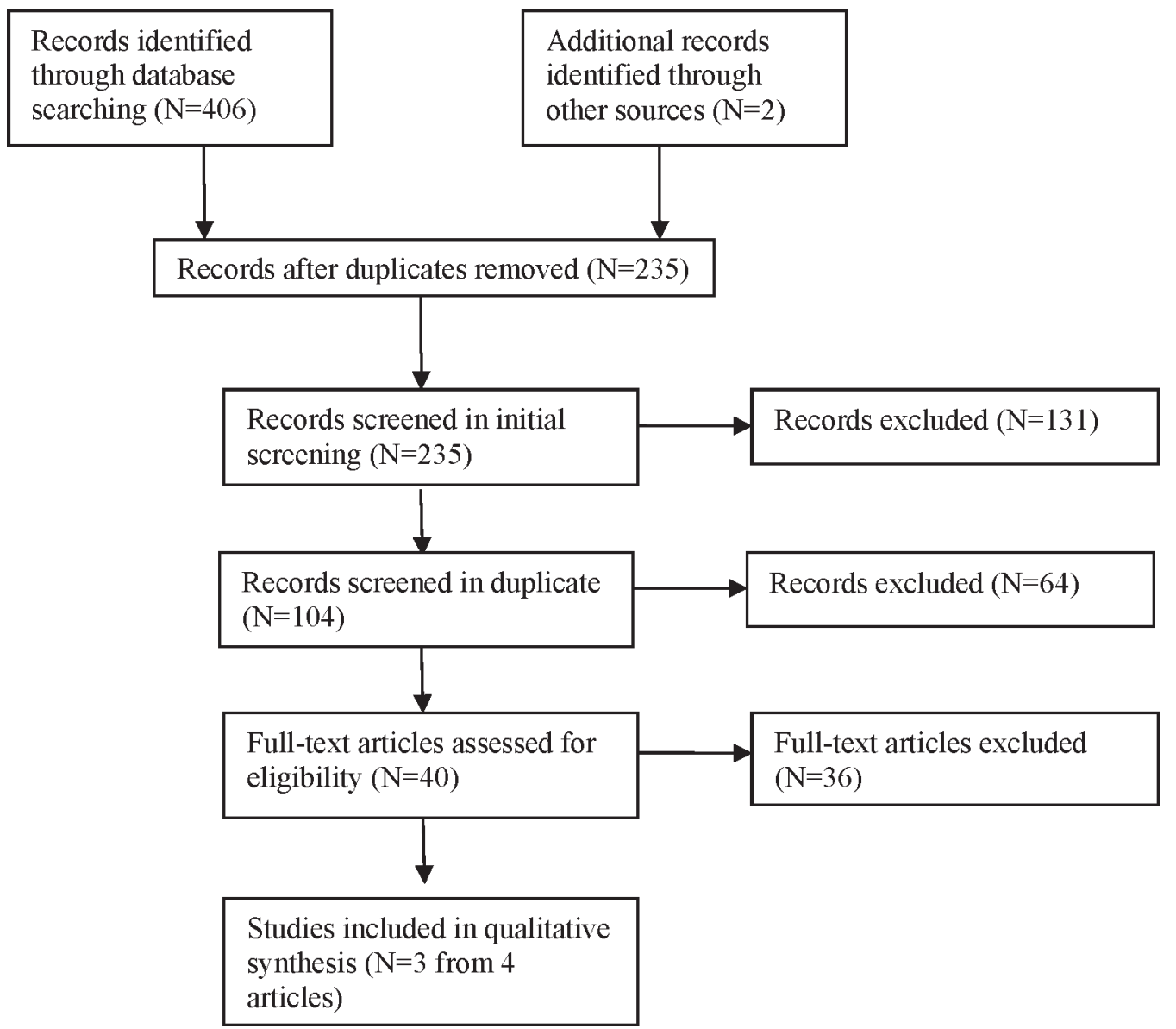

Figure 1 Disposition of citations during the search and screening process.

$0.45,95 \%$ CI 0.25 to 0.81$)$ and the partially stand-alone site (aOR $0.53,95 \% \mathrm{CI} 0.31$ to 0.90 ), but there was no difference in satisfaction between the fully integrated and fully stand-alone sites. ${ }^{26}$ There was no difference in satisfaction by gender (aOR comparing men to women: 0.88 , $95 \%$ CI 0.53 to 1.43$).{ }^{27}$ A very small number of clients were referred for STI screening (1-2 per clinic) ${ }^{28}$

\section{DISCUSSION}

Despite significant STI burden among women living with HIV and increased attention to integration of services, there is only modest evidence on the impact of integrating STI services into HIV care and treatment centres. We identified just three studies from two countries that provided comparative data on our outcomes of interest. In two studies from the UK, quality and uptake of STI services seemed to improve following introduction of new sexual health clinics into existing HIV services. However, in Swaziland, people living with HIV generally reported higher satisfaction at a stand-alone HIV clinic than at integrated service sites, and clients attending the integrated sites were no more likely than those at non-integrated sites to have had a sexual health screening. In this latter study, a diverse range of factors related to implementation of different care models challenged the notion that integrated services are always superior or desired; instead, the authors concluded that different models may work for different types of clients and the diversity of client needs and preferences, along with health system factors, should be considered when developing integrated services. ${ }^{27}$

Our review identified only a small number of articles that met the inclusion criteria, limiting the evidence base from which we can draw conclusions. Further, the study designs were cross-sectional or serial cross-sectional with modest sample sizes, limiting the inferences that can be drawn. The number and type of outcomes were also limited. The evidence gap does not necessarily reflect the lack of integrated STI and HIV services, but rather the paucity of comparative evaluations of such integration. Notably, because many national HIV guidelines indicate that STI screening should occur within routine HIV clinical care visits, evaluations may have focused on routine programme monitoring and quality assurance rather than comparing models of service delivery. ${ }^{29}$ For example, in Scotland, an audit of facilities serving people living with HIV found that less than half of sites met the guidelines for offering STI screening and recording sexual history among at least $80 \%$ of patients within 4 weeks of diagnosis, with wide variability in performance across sites. ${ }^{30}$ In Thailand, quality improvement initiative among 12 HIV care sites documented a significant increase in coverage of STI services, including an increase from $0 \%$ 


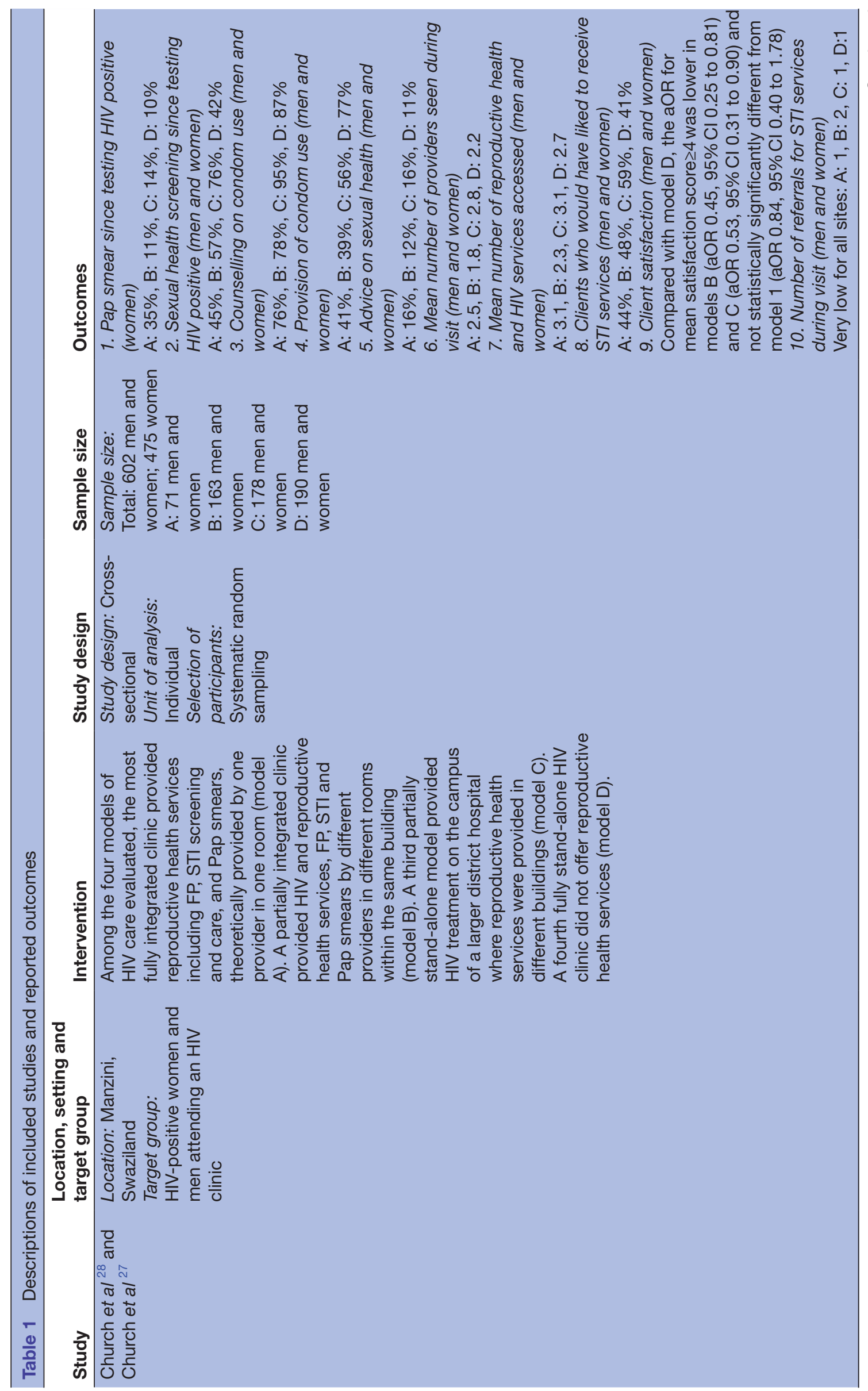




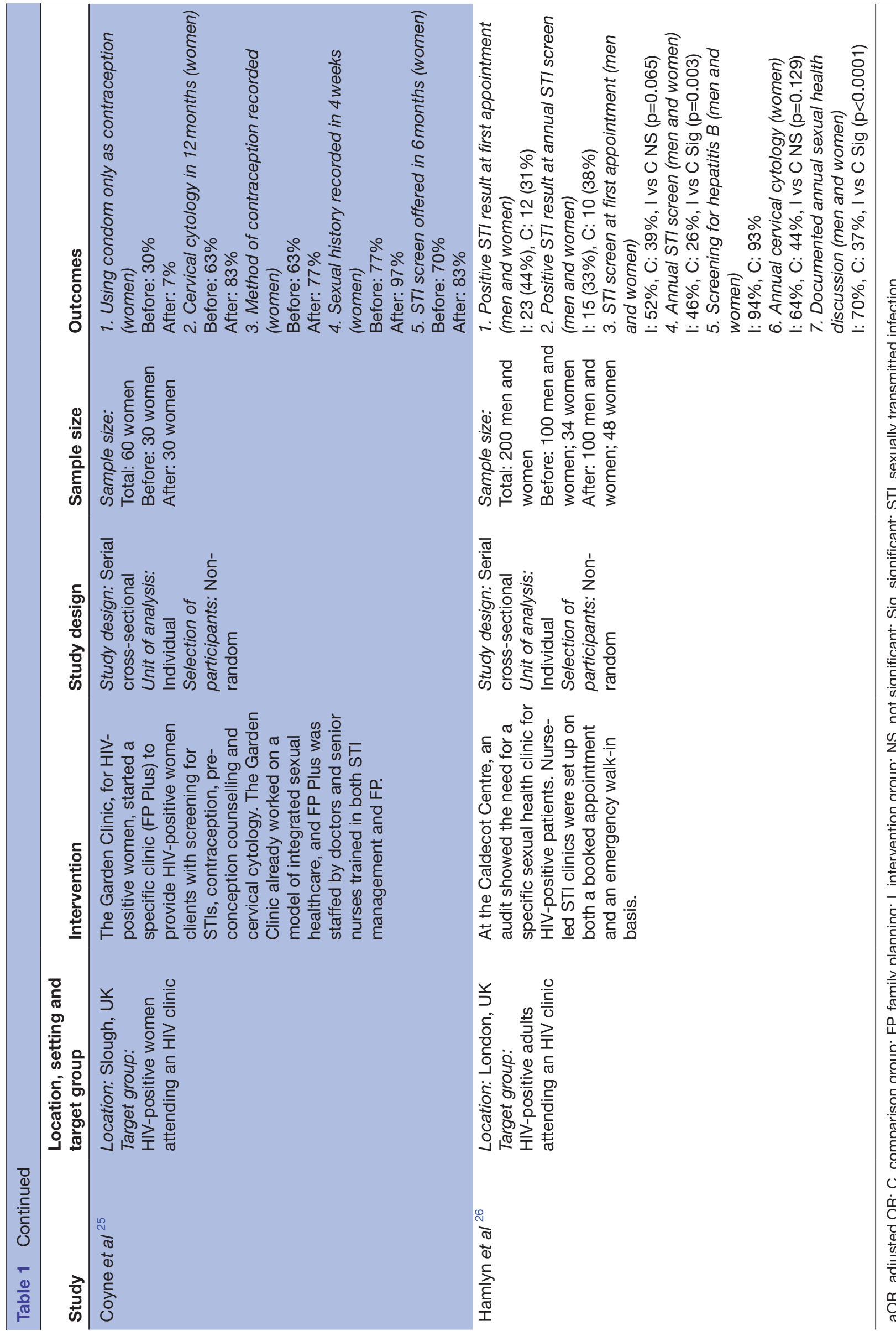




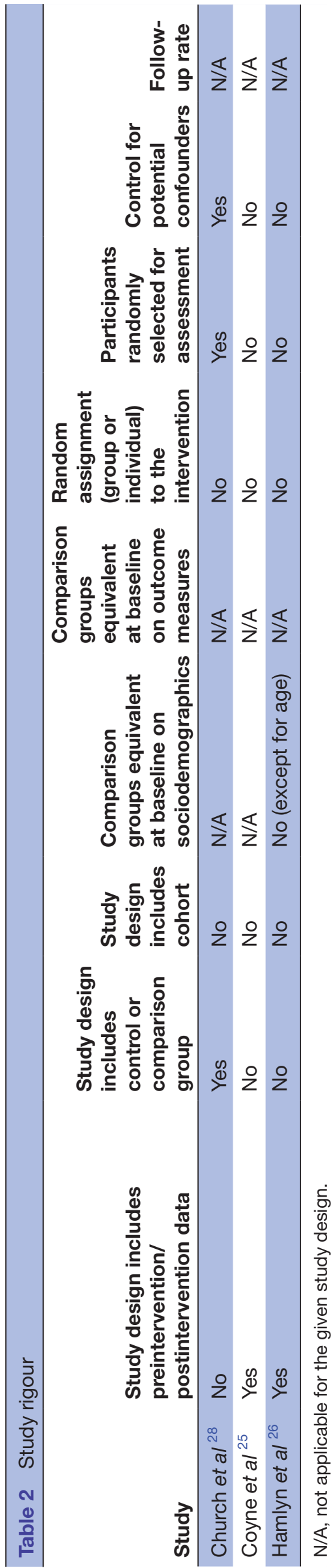

to $94 \%$ in median coverage for syphilis serology, and an increase from $0 \%$ to $67 \%$ in cervical cancer screening. ${ }^{29}$ As part of the quality improvement initiative, a checklist of services that included STI screening was developed and a new standard operating procedure was initiated offering routine gynaecological examination and Pap smears to all HIV-infected women. In settings where STI services are available in HIV clinics, quality improvement and performance monitoring frameworks may be valuable approaches to improve outcomes, while also documenting service delivery strategies and coverage.

Further documentation of diverse service models using comparative designs would help to inform programme implementation. However, there is evidence from community-based clinic settings that STI screening can be increased at relatively low cost through strategies such as the strategic placement of specimen collection materials or automatic specimen collection as part of a routine visit, the use of electronic health records and the use of patient reminders (via text, telephone and postcards). ${ }^{31}$ Such strategies would likely work in HIV care and treatment settings as well.

Several service integration initiatives hold promise for better provision of STI services within HIV care and treatment settings. Many PEPFAR-supported sites have rolled out elements of positive health, dignity and prevention which includes STI services for people living with HIV, so in future years more evidence of STI/HIV integration may be forthcoming, particularly from high-HIV burden settings. ${ }^{32}$ The integration of cervical cancer screening in HIV treatment sites in resource-limited settings in recent years has demonstrated feasibility and acceptability. ${ }^{33} 34$ The creation of private spaces for pelvic examinations provides an opportunity for STI screening among HIV-infected women. In the USA, women living with HIV had 1.9 times the odds of having a Pap smear in the last year if gynaecology services were co-located with their primary HIV care $^{34}$ and a recent study found that women with HIV were significantly more likely to have been screened for gonorrhoea and chlamydia if they had also had a Pap smear in the past year. ${ }^{33}$

As country initiatives in the elimination of mother-tochild transmission and Option B+ (immediate initiation of pregnant women on antiretroviral therapy) are expanded through the Start Free Stay Free AIDS Free framework of the Global Action Plan, ${ }^{35}$ more women living with HIV are being diagnosed in antenatal and postnatal care settings where HIV care and treatment is also being provided. With the WHO strategy for dual elimination of HIV and syphilis, ${ }^{36}$ antenatal and postnatal care settings may become key sites for the integration of STI services with HIV care and treatment. Further, antenatal care settings and other maternal, neonatal and child health services may require integration with STI services regardless of whether HIV care and treatment services are also provided, as the assumption that sexual and reproductive health services are already a comprehensive, integrated set of services is often not accurate. 
In line with a people-centred approach, grounded in principles of human rights, gender equality and health equity, the WHO global strategies on HIV, STIs and viral hepatitis aim to facilitate people's access to information, improve access to treatment and comprehensive long-term care when needed and challenge pervasive stigmatisation and discrimination. The provision of STI services within HIV treatment settings is one way to reach many national STI screening guidelines for women living with HIV. Despite the limited evidence base, the studies identified in this review did document the feasibility of integrating STI services into HIV care and treatment settings and the potential for positive outcomes of such integration. Programmes should be encouraged by this evidence to critically consider whether integration might prove beneficial in their particular settings to improve access to comprehensive, holistic services that address the sexual and reproductive health needs of women living with HIV.

Correction notice This paper has been amended since it was published Online First. Owing to a scripting error, some of the publisher names in the references were replaced with 'BMJ Publishing Group'. This only affected the full text version, not the PDF. We have since corrected theseerrors and the correct publishers have been inserted into the references.

Acknowledgements The authors thank Namratha Rao, Sophie Morse and Ping Teresa Yeh for their assistance with citation screening and formatting. They also thank the authors of the previous systematic review and Hacsi Horvath for their collaborations on previous work which informed this review. The authors are grateful to Anne Monroe for her inputs and discussion. Finally, they thank Jon Hopkins for his review and comments on the manuscript.

Contributors CEK developed the data collection tools with input from SAH. CEK and SAH led the search, screening and data abstraction processes. CEK drafted the initial manuscript. All authors developed the study protocol, reviewed and approved the final manuscript draft and interpretations.

Funding This review was funded by the WHO, Department of Reproductive Health and Research.

Competing interests None declared.

Provenance and peer review Not commissioned; externally peer reviewed.

Data sharing statement All data used in this manuscript come from previously published articles. Data extracted as part of the review are available in this manuscript. No additional data are available.

Open Access This is an Open Access article distributed in accordance with the Creative Commons Attribution Non Commercial (CC BY-NC 4.0) license, which permits others to distribute, remix, adapt, build upon this work non-commercially, and license their derivative works on different terms, provided the original work is properly cited and the use is non-commercial. See: http://creativecommons.org/ licenses/by-nc/4.0/

(c) Article author(s) (or their employer(s) unless otherwise stated in the text of the article) 2017. All rights reserved. No commercial use is permitted unless otherwise expressly granted.

\section{REFERENCES}

1. United Nations General Assembly. Transforming our world: the 2030 Agenda for Sustainable Development. New York: United Nations, 2016. https://sustainabledevelopment.un.org/post2015/transformi ngourworld. (accessed 19 Aug 2016).

2. World Health Organization. Draft global health sector strategies on HIV, 2016-2021. Geneva: World Health Organization, 2016. http:// www.who.int/hiv/strategy2016-2021/ghss-hiv/en. (accessed 19 Aug 2016).

3. World Health Organization. Draft global health sector strategies on viral hepatitis, 2016-2021. Geneva: World Health Organization, 2016. http://www.who.int/hepatitis/strategy2016-2021/ghss-hep/en/. (accessed 19 Aug 2016).

4. World Health Organization. Global health sector strategies on sexually transmitted infections, 2016-2021. Geneva: World Health Organization, 2016. http://www.who.int/reproductivehealth/ publications/rtis/ghss-stis/en/. (accessed 20 Feb 2017).

5. World Health Organization, United Nations Population Fund (UNFPA). Sexual and reproductive health of women living with HIVI AIDS: guidelines on care, treatment and support for women living with HIVIAIDS and their children in resource-constrained settings. Geneva: World Health Organization, 2016. http://www.who.int/ reproductivehealth/publications/gender rights/srhr-women-hiv/en/. (accessed 19 Aug 2016).

6. Naresh A, Beigi R, Woc-Colburn L, et al. The bidirectional interactions of human immunodeficiency Virus- 1 and sexually transmitted infections. Infectious Diseases in Clinical Practice 2009;17:362-73.

7. Kalichman SC, Pellowski J, Turner C. Prevalence of sexually transmitted co-infections in people living with HIV/AIDS: systematic review with implications for using HIV treatments for prevention. Sex Transm Infect 2011;87:183-90.

8. World Health Organization. Essential Prevention and Care Interventions for adults and adolescents living with HIV in ResourceLimited Settings. Geneva: World Health Organization, 2008. http:// www.who.int/hiv/pub/plhiv/plhiv_treatment_care.pdf?ua=1. (accessed 19 Aug 2016).

9. World Health Organization. Consolidated guidelines on the use of antiretroviral drugs for treating and preventing HIV infection -. 2nd ed. Geneva: World Health Organization, 2016. http://apps.who. int/iris/bitstream/10665/208825/1/9789241549684_eng.pdf?ua=1 (accessed 19 Aug 2016).

10. The U. S. President's Emergency Plan for AIDS Relief (PEPFAR). Guidance for the Prevention of Sexually Transmitted HIV Infections. Washington, D.C.: PEPFAR, 2011. http://www.pepfar.gov/ documents/organization/171303.pdf. (accessed 19 Aug 2016).

11. Hembrom R, Goodall L, Bateman V, et al. BASHH Scotland/ Scottish HIV and AIDS group national audit 2009-2010: sexual health care for people living with HIV. Int J STD AIDS 2012;23:439-40.

12. Kahle $\mathrm{E}$, Zhang $\mathrm{Q}$, Golden $\mathrm{M}$, et al. Trends in evaluation for sexually transmitted infections among HIV-infected people, King County, Washington. Sex Transm Dis 2007;34:940-6.

13. Klausner JD, Stanley H, Stansell J. STD screening among HIVinfected patients in care, San Francisco. AIDS Patient Care STDS 2001;15:73-6.

14. Phipps W, Stanley H, Kohn R, et al. Syphilis, Chlamydia, and gonorrhea screening in HIV-infected patients in primary care, San Francisco, California, 2003. AIDS Patient Care STDS 2005;19:495-8.

15. Flagg EW, Weinstock HS, Frazier EL, et al. Bacterial sexually transmitted infections among HIV-infected patients in the United States: estimates from the medical monitoring project. Sex Transm Dis 2015;42:171-9.

16. Atun $\mathrm{R}$, de Jongh $\mathrm{T}$, Secci $\mathrm{F}$, et al. A systematic review of the evidence on integration of targeted health interventions into health systems. Health Policy Plan 2010;25:1-14.

17. World Health Organization. Integrated health services - what and why? Technical brief No.1, 2008. Geneva: World Health Organization, 2008. http://www.who.int/healthsystems/service_delivery_techbrief1. pdf. (accessed 19 Aug 2016).

18. World Health Organization. Consolidated guideline on sexual and reproductive health and rights of women living with HIV. Geneva: World Health Organization, 2017. http://apps.who.int/iris/bitstream/ 10665/254634/1/WHO-RHR-17.03-eng.pdf?ua. (accessed 23 Feb 2017).

19. Moher D, Liberati A, Tetzlaff J, et al. Preferred reporting items for systematic reviews and meta-analyses: the PRISMA statement. Int $J$ Surg 2010;8:336-41.

20. Brickley DB, Almers L, Kennedy CE, et al. Sexual and reproductive health services for people living with HIV: a systematic review. AIDS Care 2011;23:303-14.

21. Joseph Davey D, Myer L, Bukusi E, et al. Integrating human immunodeficiency virus and Reproductive, Maternal and Child, and tuberculosis Health Services within National Health Systems. Curr HIVIAIDS Rep 2016;13:170-6.

22. Haberlen SA, Narasimhan M, Beres LK, et al. Integration of Family Planning Services into HIV Care and Treatment Services: A systematic review. Stud Fam Plann 2017;29.

23. Kennedy C, O'Reilly K, Medley A, et al. The impact of HIV treatment on risk behaviour in developing countries: a systematic review. AIDS Care 2007;19:707-20. 
24. Denison JA, O'Reilly KR, Schmid GP, et al. HIV voluntary counseling and testing and behavioral risk reduction in developing countries: a meta-analysis, 1990--2005. AIDS Behav 2008;12:363-73.

25. Coyne KM, Hawkins F, Desmond N. Sexual and reproductive health in HIV-positive women: a dedicated clinic improves service. Int J STD AIDS 2007;18:420-1.

26. Hamlyn E, Barrett S, Kelsey J, et al. Improvement in screening for sexually transmitted infections in HIV-positive patients following implementation of a nurse-led clinic. Int J STD AIDS 2007;18:424-6.

27. Church K, Wringe A, Fakudze $P$, et al. The relationship between service integration and client satisfaction: a mixed methods case study within HIV services in a high prevalence setting in Africa. AIDS Patient Care STDS 2012;26:662-73.

28. Church K, Wringe A, Lewin S, et al. Exploring the feasibility of Service integration in a Low-Income Setting: a Mixed methods Investigation into different models of Reproductive Health and HIV Care in Swaziland. PLoS One 2015;10:e0126144.

29. Thanprasertsuk S, Supawitkul S, Lolekha R, et al. HIVQUAL-T: monitoring and improving HIV clinical care in Thailand, 2002-08. Int $J$ Qual Health Care 2012;24:338-47.

30. Hembrom R, Goodall L, Bateman V, et al. BASHH Scotland/Scottish HIV and AIDS group national audit 2009-2010: sexual health care for people living with HIV. Int J STD AIDS 2012;23:439-40.
31. Taylor MM, Frasure-Williams J, Burnett P, et al. Interventions to improve sexually transmitted disease screening in Clinic-Based settings. Sex Transm Dis 2016;43(2 Suppl 1):S28-S41.

32. Medley A, Bachanas P, Grillo M, et al. Integrating prevention interventions for people living with HIV into care and treatment programs: a systematic review of the evidence. J Acquir Immune Defic Syndr 2015;68(Suppl 3):S286-96.

33. Frazier EL, Sutton MY, Tie Y, et al. Screening for cervical Cancer and sexually transmitted diseases among HIV-Infected women. J Womens Health 2016;25:124-32.

34. Stein MD, Cunningham WE, Nakazono T, et al. Screening for cervical Cancer in HIV-infected women receiving care in the United States. J Acquir Immune Defic Syndr 2001;27:463-6.

35. Joint United Nations Programme on HIV/AIDS. Start free, stay free, AIDS free: a super-fast-track framework for ending AIDS among children, adolescents, and young women by 2020. Geneva: UNAIDS, 2016. https://free.unaids.org/. (accessed 23 Feb 2017).

36. World Health Organization. Elimination of mother-to-child transmission (EMTCT) of HIV and syphilis: global guidance on criteria and processes for validation. Geneva: World Health Organization, 2014. http://www.who.int/reproductivehealth/publications/rtis/ 9789241505888/en/ (accessed 20 Feb 2017). 